\title{
Radar Cross-Section Measurements of V22 Blade Tip with and without LLNL Tipcap Reflector
}

\author{
D. Poland and R. Simpson
}

July 1, 2000

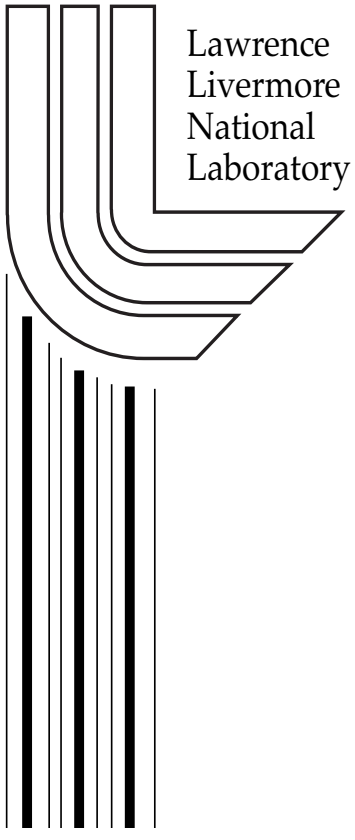




\section{DISCLAIMER}

This document was prepared as an account of work sponsored by an agency of the United States Government. Neither the United States Government nor the University of California nor any of their employees, makes any warranty, express or implied, or assumes any legal liability or responsibility for the accuracy, completeness, or usefulness of any information, apparatus, product, or process disclosed, or represents that its use would not infringe privately owned rights. Reference herein to any specific commercial product, process, or service by trade name, trademark, manufacturer, or otherwise, does not necessarily constitute or imply its endorsement, recommendation, or favoring by the United States Government or the University of California. The views and opinions of authors expressed herein do not necessarily state or reflect those of the United States Government or the University of California, and shall not be used for advertising or product endorsement purposes.

This work was performed under the auspices of the U. S. Department of Energy by the University of California, Lawrence Livermore National Laboratory under Contract No. W-7405-Eng-48.

This report has been reproduced directly from the best available copy.

Available electronically at http://www.doc.gov/bridge

Available for a processing fee to U.S. Department of Energy

And its contractors in paper from

U.S. Department of Energy

Office of Scientific and Technical Information

P.O. Box 62

Oak Ridge, TN 37831-0062

Telephone: (865) 576-8401

Facsimile: (865) 576-5728

E-mail: reports@adonis.osti.gov

Available for the sale to the public from

U.S. Department of Commerce

National Technical Information Service

5285 Port Royal Road

Springfield, VA 22161

Telephone: (800) 553-6847

Facsimile: (703) 605-6900

E-mail: orders@ntis.fedworld.gov

Online ordering: http://www.ntis.gov/ordering.htm

OR

Lawrence Livermore National Laboratory

Technical Information Department's Digital Library

http:/ / www.llnl.gov/tid/Library.html 


\title{
Radar Cross-Section Measurements of V22 Blade Tip with and without LLNL Tipcap Reflector
}

\author{
Doug Poland, Robert Simpson \\ July 2000
}

\author{
Lawrence Livermore National Laboratory \\ 7000 East Avenue \\ Livermore, CA 94550
}




\section{Introduction}

It is desired to quantify the effect, in terms of radar cross-section (RCS), of the addition of a small aluminum reflector to the end of the V22 blades. This reflector was designed and manufactured in order to facilitate blade lag measurements by the $95 \mathrm{GHz}$ Lawrence Livermore National Laboratory (LLNL) Radar Blade Tracker (RBT) system. The reflector used in these measurements was designed and fabricated at LLNL and is pictured in Figure 1.
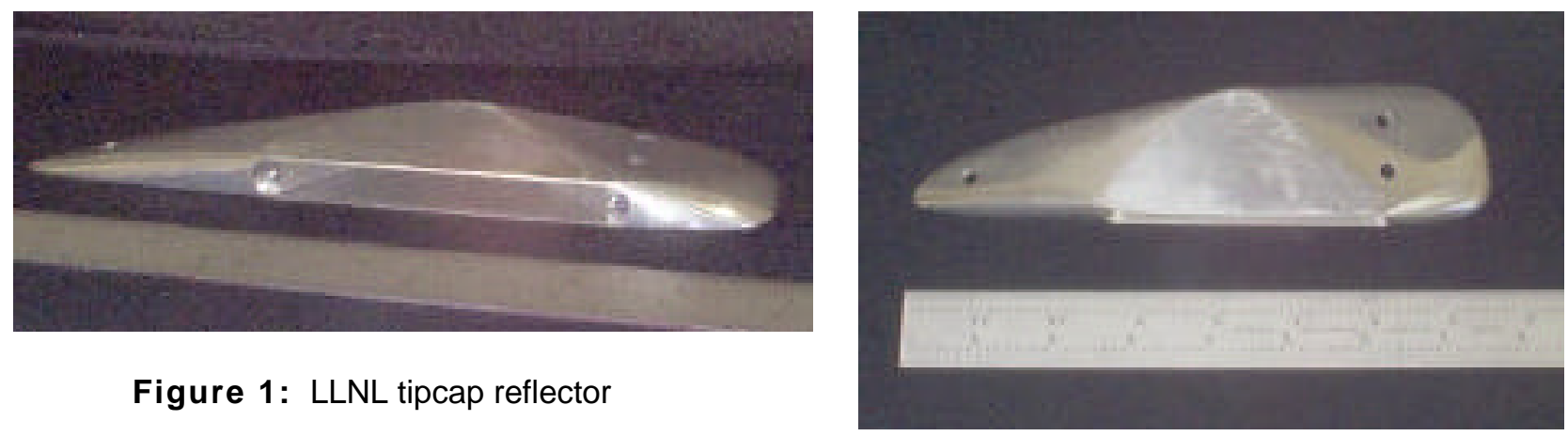

Figure 1: LLNL tipcap reflector

\section{Methodology}

Radar cross-section (RCS) measurements were performed in an anechoic chamber in Building 141 at LLNL at various blade and antenna orientations and at frequencies ranging from 1-20 GHz. This chamber is rated at $-100 \mathrm{~dB}$ over a range of $1-18 \mathrm{GHz}$. For each configuration, a dataset was taken with the standard aluminum endplate on the blade tip, and then the same measurement was repeated with the endplate replaced by the tipcap reflector.
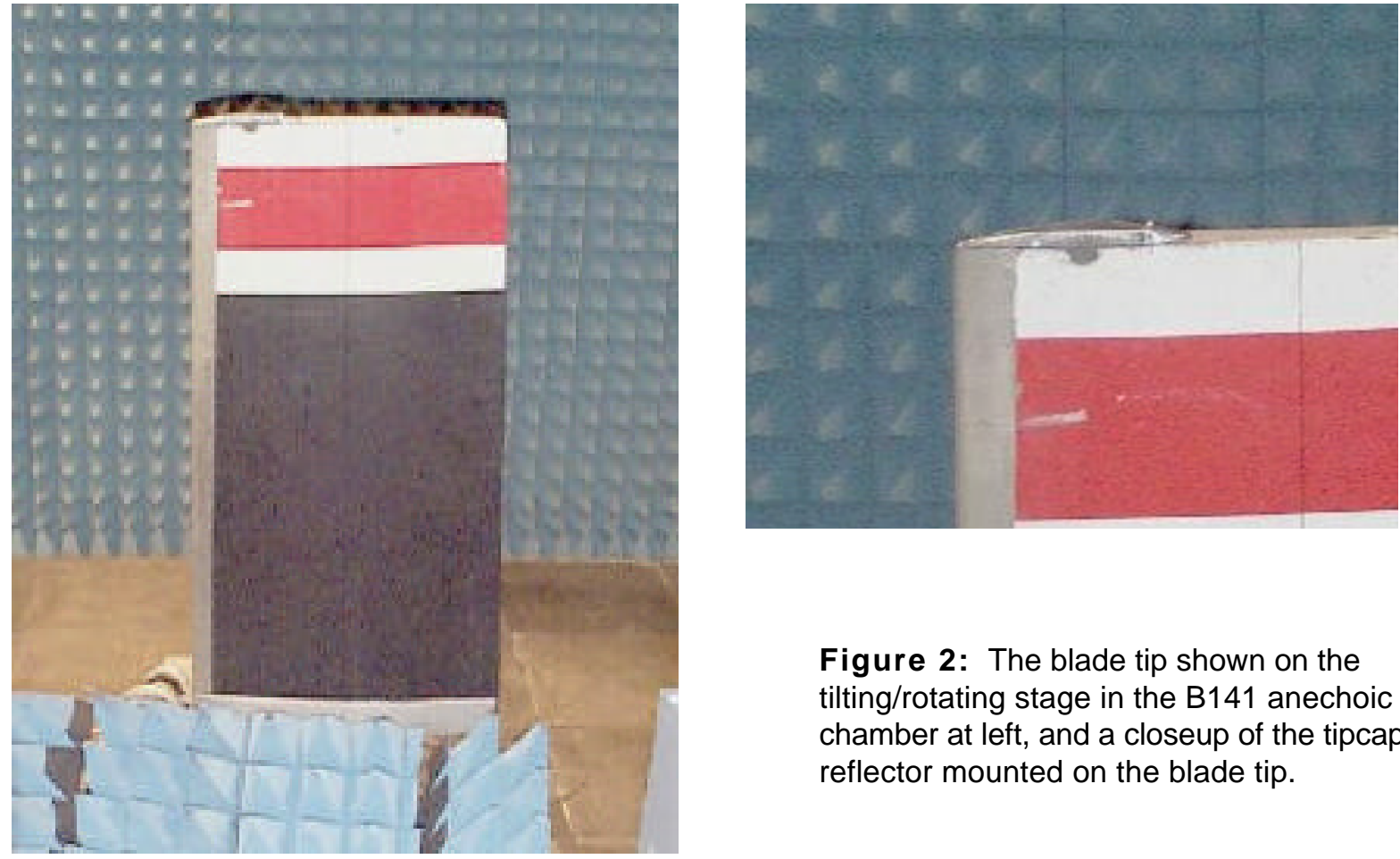

Figure 2: The blade tip shown on the tilting/rotating stage in the B141 anechoic chamber at left, and a closeup of the tipcap reflector mounted on the blade tip. 
The blade tip was set vertically upon a tilting and rotating stage which was controlled by a Newport MM3000 Motion Controller. An Apple PowerMac 8500 was used to control both the Newport and the HP 8510B Network Analyzer, coordinating stage motion and data acquisition. In order to minimize direct transmission from the transmit to the receive antenna, the transmit antenna was located closer to the target and radar absorbing material (RAM) was placed between the two. The bistatic angle was less than 10 degrees, hence the measured RCS is approximately equal to the monostatic RCS.

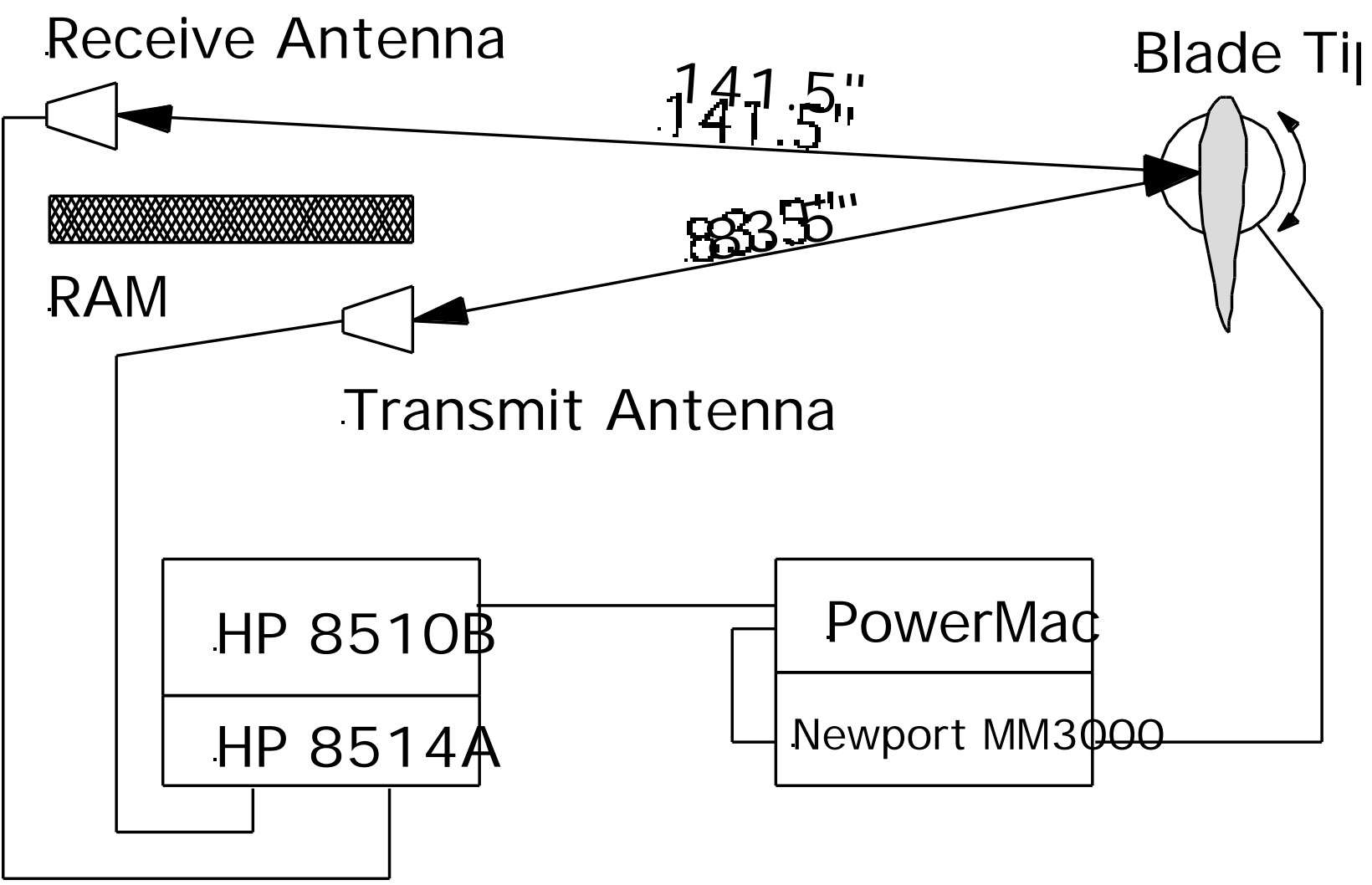

Figure 3: Schematic diagram of setup and equipment used for RCS measurements.

For each set of measurements, the calibration and measurement sequence was:

1) Set up the Network Analyzer:

Desired frequency or range of frequencies

$1 \mathrm{~K}$ averaging (take average of 1000 trials)

401 points

2) Point the antennas toward each other and perform an indirect calibration

3) Rotate the antennas so they are directed toward the blade tip

4) Put the blade in place with the endplate installed on the tip; record $S 12\left(P_{r} / P_{t}\right.$ in $\left.d B\right)$

5) Replace the endplate with the tipcap reflector and record S12

This sequence produced all of the data that was required for the RCS calculations. 
The bistatic radar equation may be written

$$
\frac{P_{r}}{P_{t}}=G_{t} \frac{1}{4 \pi R_{t}^{2}} \sigma \frac{1}{4 \pi R_{r}^{2}} \frac{G_{r} \lambda^{2}}{4 \pi}
$$

which represents the ratio of received to transmitted power when the signal is reflected off an object with RCS $\sigma$. If we point the antennas toward each other with separation $R_{c}$, there is no reflection and only one geometric loss term, giving

$$
\frac{P_{r, c}}{P_{t}}=G_{t} \frac{1}{4 \pi R_{c}^{2}} \frac{G_{r} \lambda^{2}}{4 \pi}
$$

We can use this calibration measurement to eliminate the antenna parameters from the RCS calculation:

$$
\frac{P_{r} / P_{t}}{P_{r, c} / P_{t}}=\frac{R_{c}^{2}}{4 \pi R_{t}^{2} R_{r}^{2}} \sigma
$$

where the ratio on the right-hand side is

$$
\frac{R_{c}^{2}}{4 \pi R_{t}^{2} R_{r}^{2}}=\frac{\left(39\langle 2.54)^{2}\right.}{4 \pi\left(8 3 . 5 \langle 2 . 5 4 ) ^ { 2 } \left(141.5\langle 2.54)^{2}\right.\right.}=1.36 \times 10^{-7} \mathrm{~cm}^{-2}
$$

Then rearranging yields the expression for $\sigma$ in $\mathrm{cm}^{2}$ :

$\sigma=7.35 \times 10^{6} \frac{P_{r} / P_{t}}{P_{r, c} / P_{t}}$

Expressing all quantities in $\mathrm{dB}$, then $\sigma$ in $\mathrm{dB}-\mathrm{cm}^{2}$ is

$\sigma=68.7+\left(P_{r} / P_{t}\right)-\left(P_{r, c} / P_{t}\right)$ 


\section{Results}

Presented in the following figures are the results of these measurements. Each plot shows blade tip RCS vs. angle as the blade tip is rotated through 360 degrees. In each plot, the noise floor of the instrument for the given frequency is shown in purple for comparison. The RCS of the blade tip with the standard end plate is shown in red, while the RCS of the blade tip with the tipcap reflector in place is shown in black. In most cases, the two measurements are indistinguishable. The uniform result is that the contribution of the tipcap reflector to the measured RCS of the blade tip is negligible. The various combinations of frequency, blade tip tilt and rotation, and antenna polarization did not reveal any configuration in which the effect of the tipcap reflector was distinguishable.

RCS vs. Frequency - Horizontal Polarization

The first set of measurements looked at the frequency dependence of the tipcap reflector RCS. This was done in two different ways. In the first measurement, the blade was positioned normal to the antennas with the polarization of the antennas aligned with the reflector (horizontal). With the blade stationary, the RCS measurement was performed over a range of $1-20 \mathrm{GHz}$. In the second RCS vs. Frequency measurement, various individual frequencies were used to examine the RCS as the blade was rotated.

\section{RCS vs. Tilt Angle - Vertical Polarization}

The effect of tilt was investigated as well. The frequency was set to $10 \mathrm{GHz}$ and RCS measurements were performed through a 360 degree rotation with the blade tip set to various tilt angles. The antenna polarization was vertical for these measurements. The blade was tilted forward in two degree increments. It was found that the signal degraded fairly rapidly with increasing tilt and that again there was no discernible signature from the tipcap reflector. 
V22 Blade Tip RCS (dB-cm $\left.{ }^{2}\right)-1 \mathrm{GHz}, 0^{\circ}$ Tilt

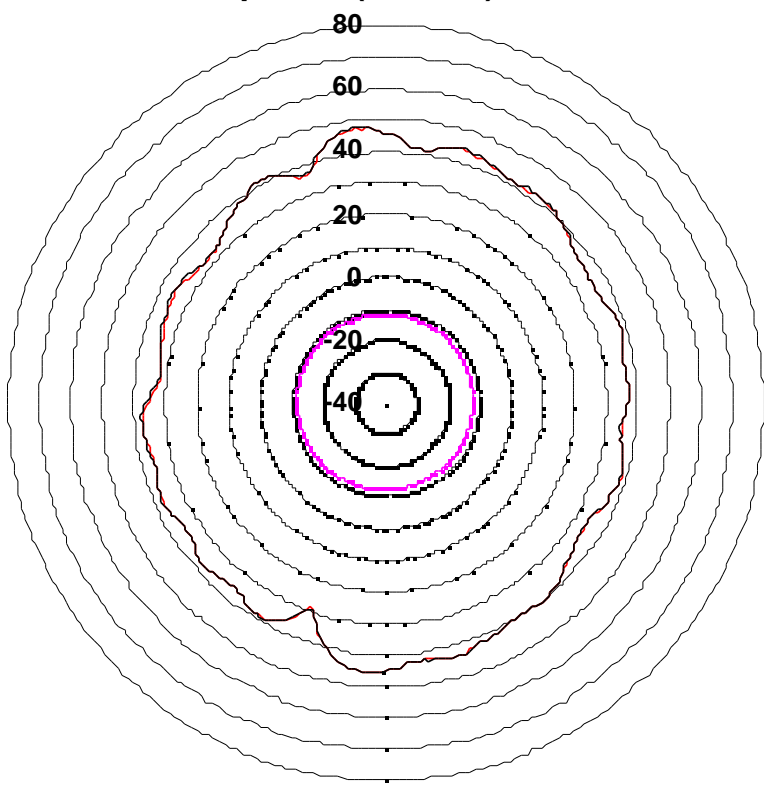

End Plate _ Reflector _ Noise Floor

V22 Blade Tip RCS (dB-cm ${ }^{2}$ ) $5 \mathrm{GHz}, 0^{\circ}$ Tilt

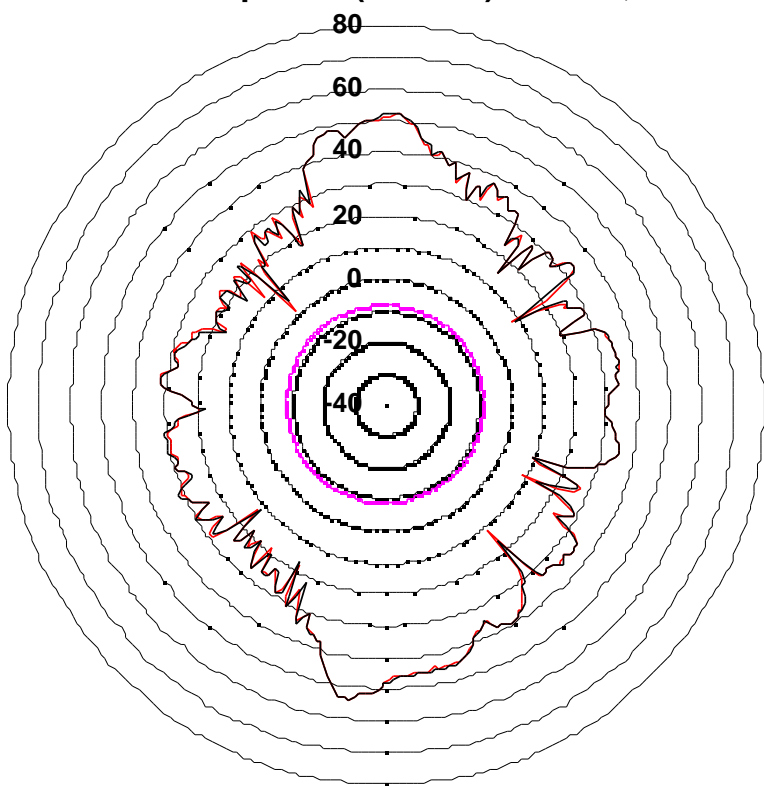

End Plate _ Reflector Noise Floor
V22 Blade Tip RCS (dB-cm²) - 2 GHz, $0^{\circ}$ Tilt

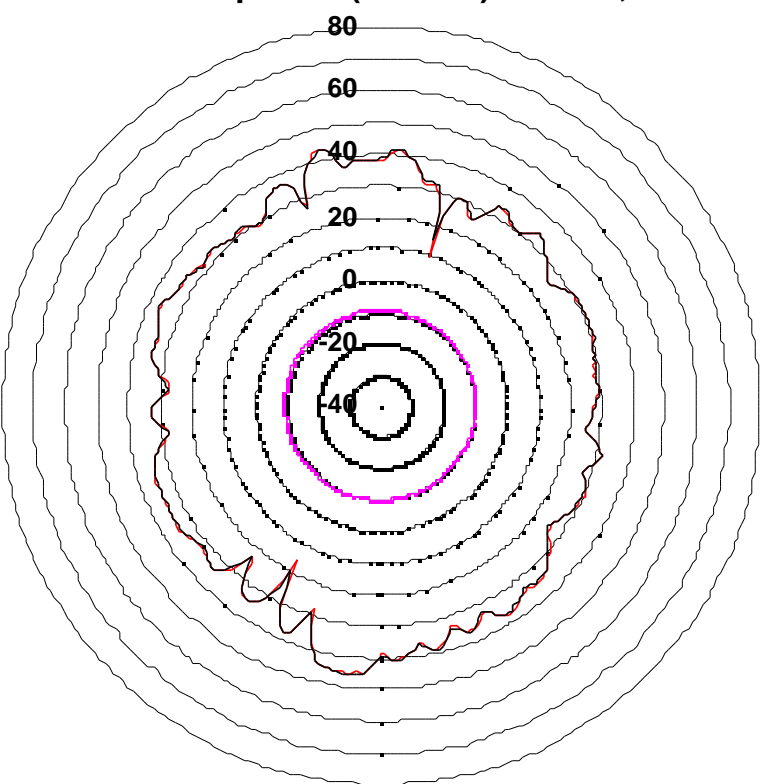

End Plate $\longrightarrow$ Reflector
V22 Blade Tip RCS (dB-cm $\left.{ }^{2}\right)-10 \mathrm{GHz}, 0^{\circ}$ Tilt

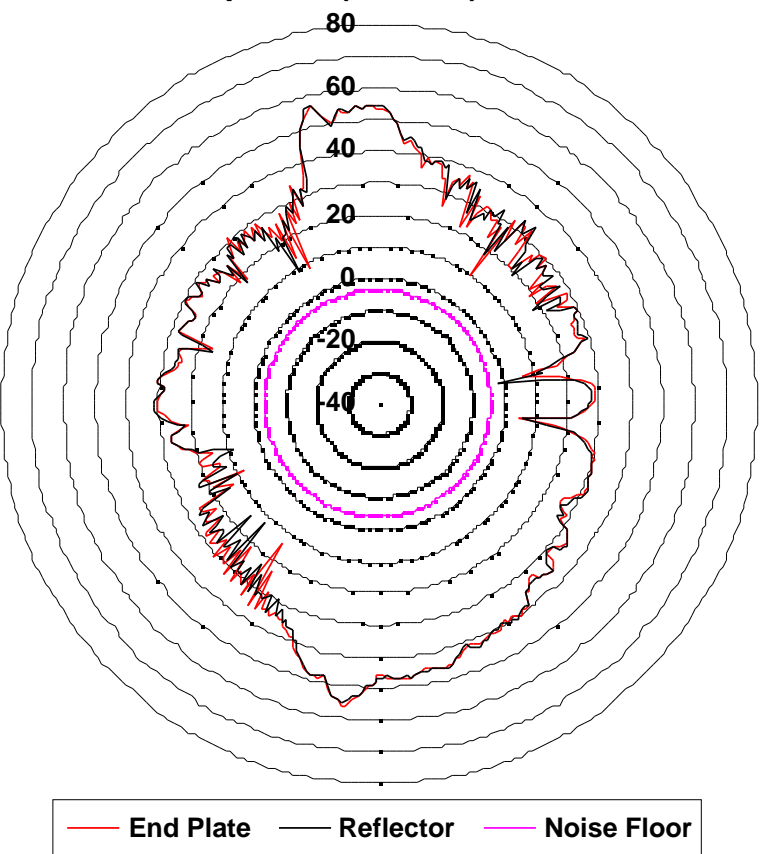

Figure 4: RCS results for $1-10 \mathrm{GHz}$; horizontal antenna polarization. 
V22 Blade Tip RCS (dB-cm²) $12 \mathrm{GHz}, 0^{\circ}$ Tilt

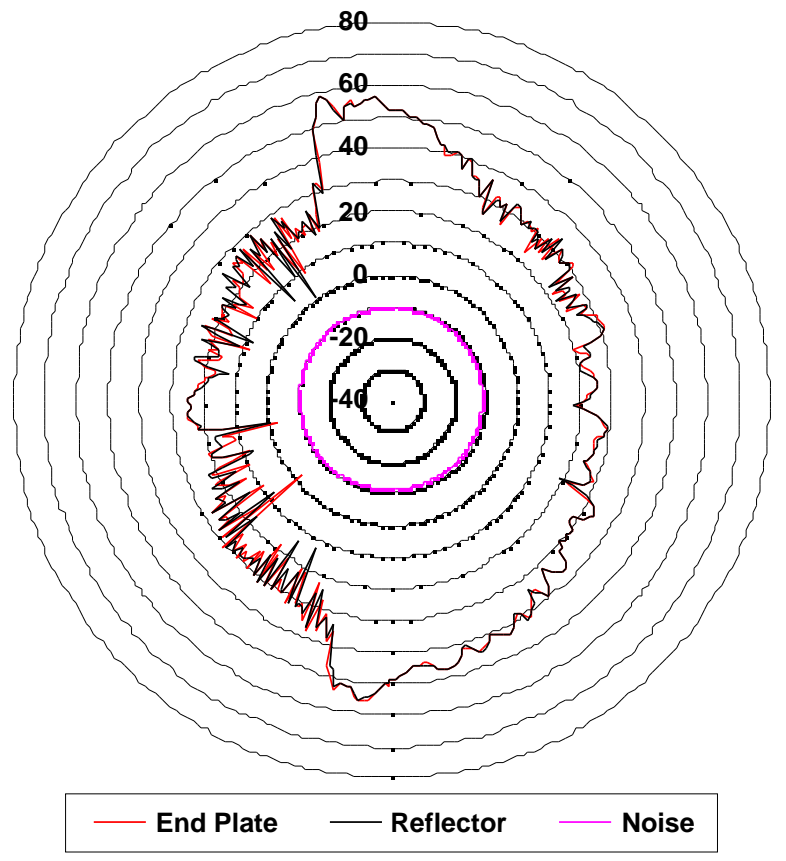

V22 Blade Tip RCS (dB-cm $\left.{ }^{2}\right)-18 \mathrm{GHz}, 0^{\circ}$ Tilt

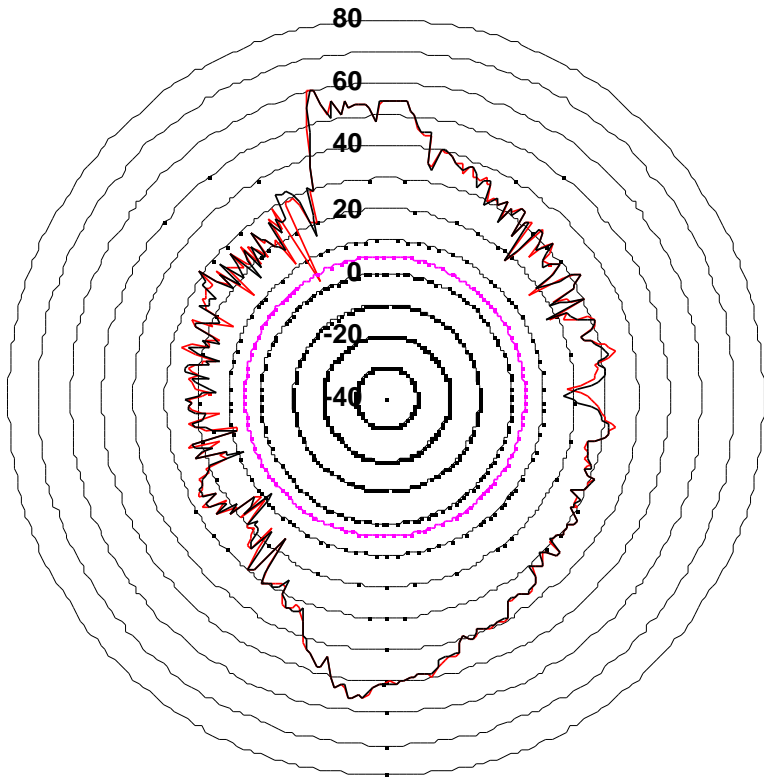

- End Plate — Reflector — Noise
V22 Blade Tip RCS (dB-cm $\left.{ }^{2}\right)-15 \mathrm{GHz}, 0^{\circ}$ Tilt

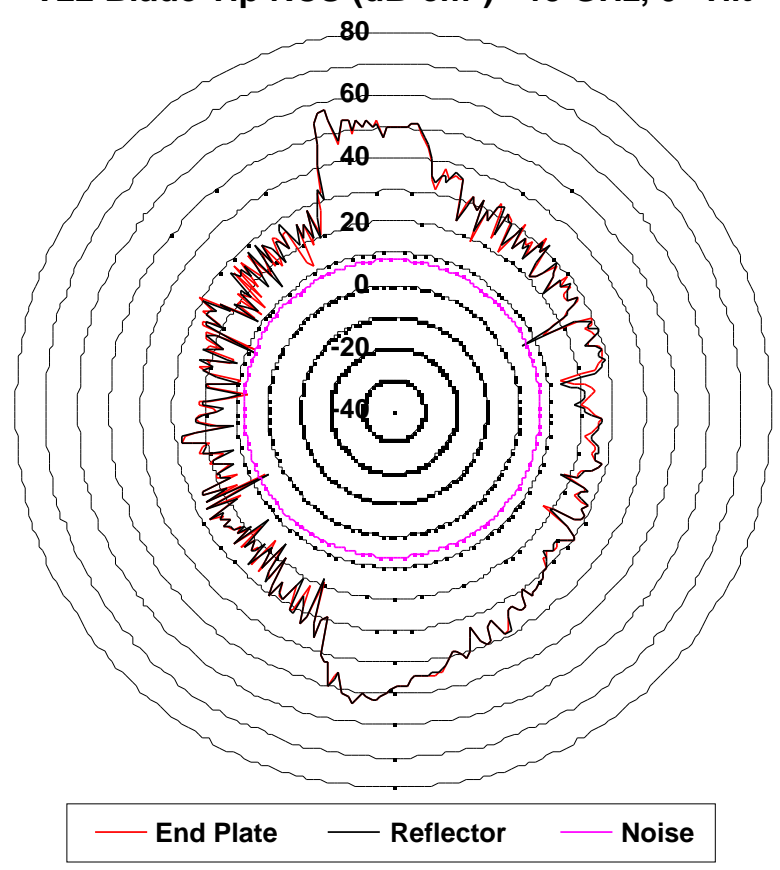

V22 Blade Tip RCS (dB-cm $\left.{ }^{2}\right)-20 \mathrm{GHz}, 0^{\circ}$ Tilt

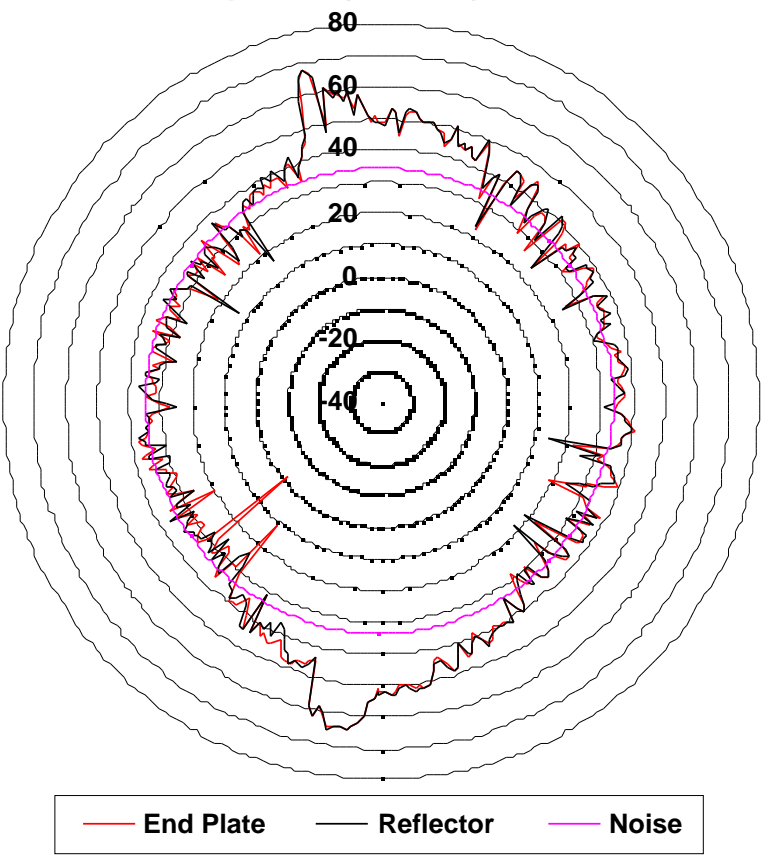

Figure 5: RCS results for $12-20 \mathrm{GHz}$; horizontal antenna polarization. 
V22 Blade Tip RCS (dB-cm²) - $10 \mathrm{GHz}, 0^{\circ}$ Tilt Vertical Antenna Polarization

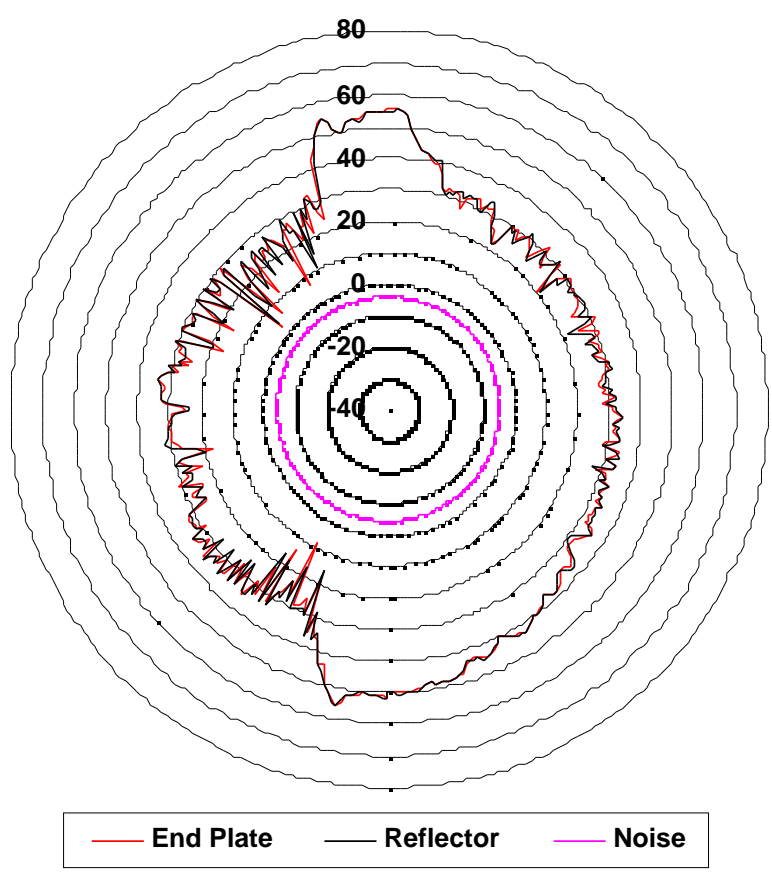

V22 Blade Tip RCS (dB-cm $\left.{ }^{2}\right)-10 \mathrm{GHz}, 4^{\circ}$ Tilt Vertical Antenna Polarization

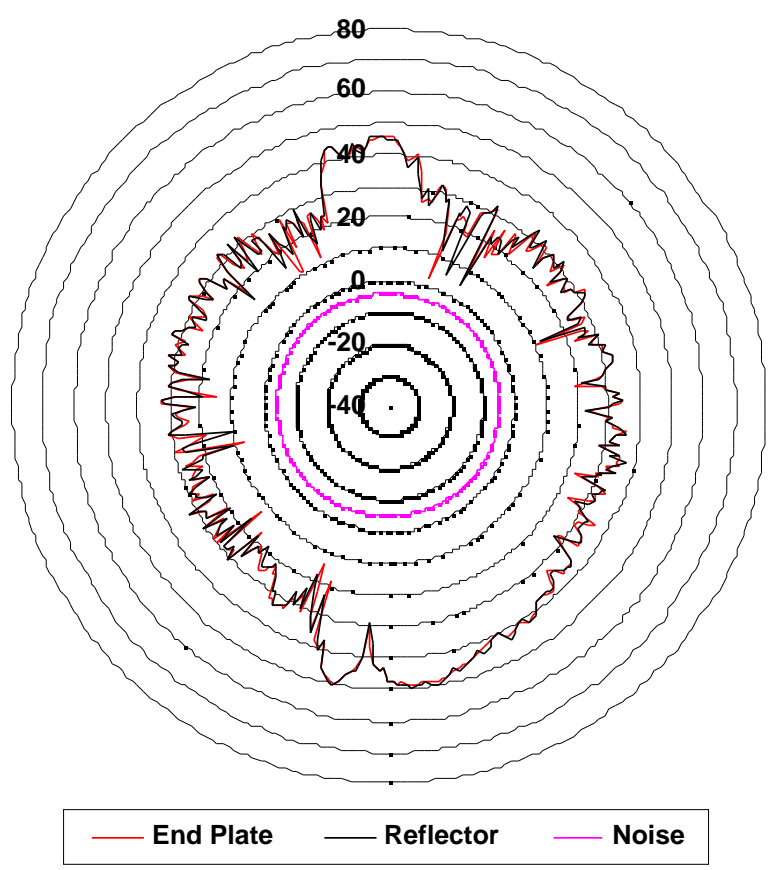

V22 Blade Tip RCS (dB-cm²) - $10 \mathrm{GHz}, 2^{\circ}$ Tilt Vertical Antenna Polarization

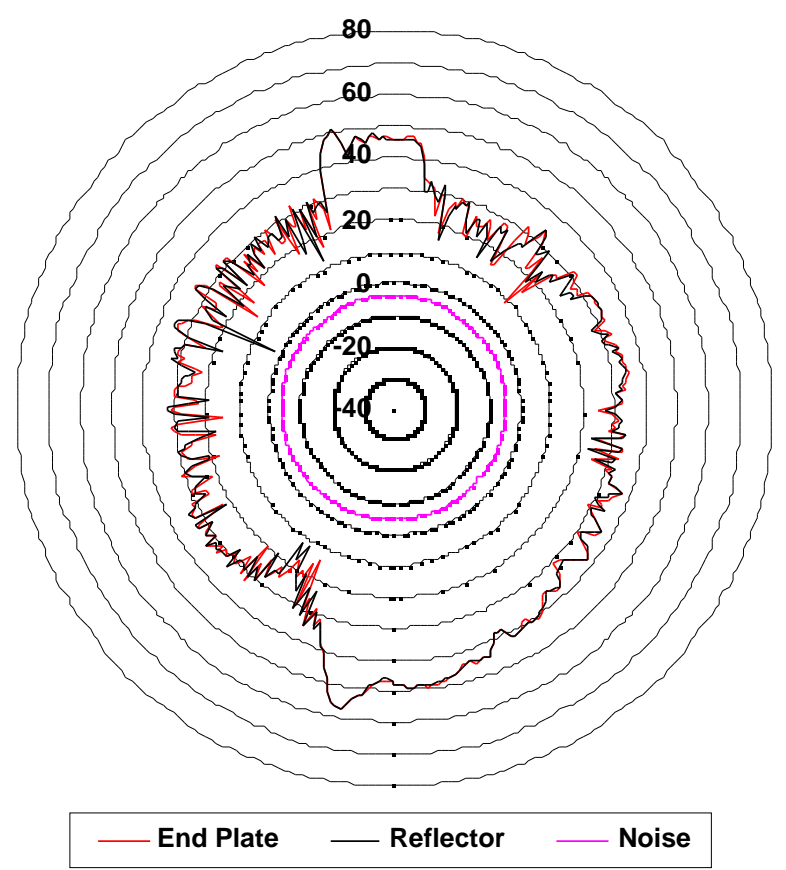

V22 Blade Tip RCS (dB-cm²) - $10 \mathrm{GHz}, 6^{\circ}$ Tilt Vertical Antenna Polarization

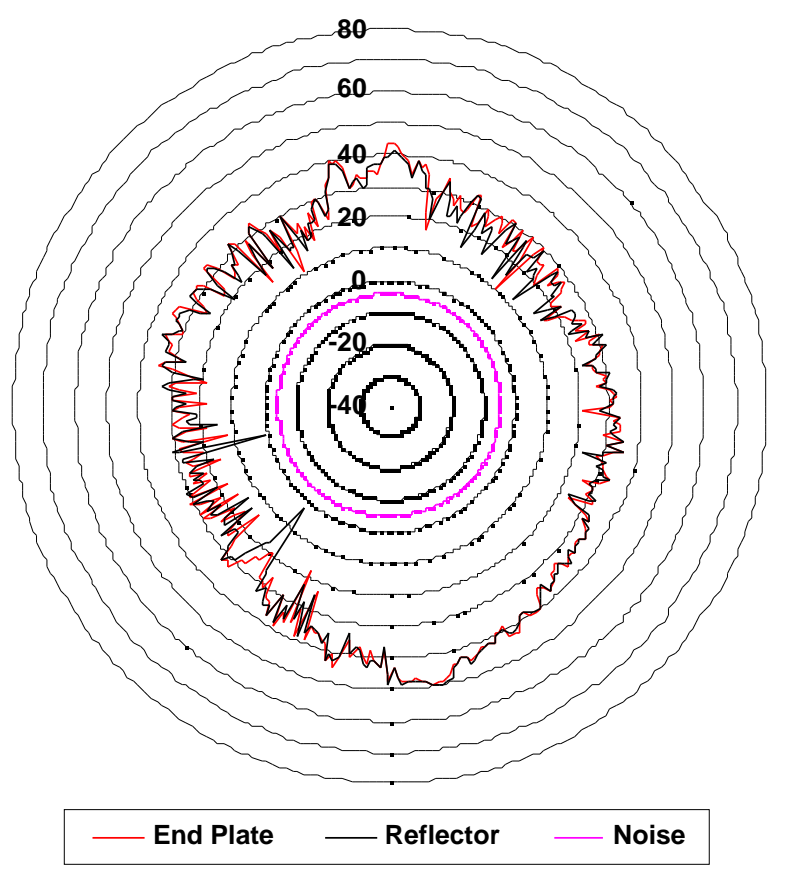

Figure 6: RCS results for various tilt angles at $10 \mathrm{GHz}$; vertical antenna polarization. 